\title{
4. ANALOGÍA Y APOLOGÉTICA \\ EN PASCAL
}

\section{INTRODUCCIÓN}

En estas páginas, me detendré a dialogar con Pascal, quien tuvo un espíritu analógico, tan fuerte como su espíritu de fineza, junto a su espíritu de geometría. Al parecer, es inagotable, sus pensamientos no dejan de alimentar nuestro espíritu con la reflexión. Y un espíritu analógico, como el suyo, es un aliciente para mí en cuanto a la enseñanza que de él pueda recibir. Es mucho lo que se ve que puede brindarnos, si estamos atentos.

Así, pues, elaboraré unos cuantos pensamientos suyos, para después aprender la carga analógica que contienen, es decir, la enseñanza que me dan para el pensamiento de la analogía, de la proporción, que tanto buscó, en medio de la desproporción del universo, para una hermenéutica analógica. Tal será el provecho que saquemos de su consideración, aguzar nuestro espíritu de analogía, contrastado con el espíritu de fineza y de geometría, que también tuvo en tanta magnitud.

\section{PASCAL: LA RAZÓN Y EL CORAZÓN}

Blaise Pascal (1623-1662) estuvo muy vinculado al racionalismo de Descartes, porque lo conoció y discutió con él su invento de una 
máquina matemática, aunque Descartes estuvo más interesado en sus experimentos sobre el vacío. Por ser Descartes un gran matemático, Pascal lo consideró también un gran filósofo, pero en filosofía lo sometió a muchas objeciones y a una profunda crítica.

Así, en medio de la modernidad, y en relación con el propio Descartes, Pascal critica el racionalismo, de manera muy semejante a los cuestionamientos que se le hacen en la posmodernidad. Por eso, tiene gran actualidad. Se opuso al cientificismo y trató de articular o concordar la razón y la fe (Villar, 1987, pp. 177 y ss.; Gómez, 1992, pp. 32 y ss.). Las posturas de ambos son muy diferentes, por ejemplo en la aceptación de la prueba anselmiana y el argumento de la apuesta, o en la distinción del espíritu geométrico y el espíritu de fineza.

Considera la filosofía de Descartes, en general, inútil e incierta, además penosa. Todo ello porque trata de profundizar demasiado en la ciencia, es decir, porque se basa mucho en la ciencia, confía excesivamente en ella. En su física mecanicista usa a Dios como deus ex machina, y, si hubiera podido, prescindía de Él, pero lo necesitaba para dar el inicio al movimiento de esa gran máquina. A pesar de la pretensión criticista de la filosofía cartesiana, encuentra en ella una notable soberbia y un fuerte dogmatismo.

Las concepciones de la racionalidad, la ciencia y el método son divergentes, y la de Pascal constituye una alternativa. Para Descartes, la naturaleza tiene leyes universales y necesarias, para Pascal son probables y contingentes (Villar, 2010, pp. 265 y ss.). Para Descartes, el conocimiento es neutro e igual en todas partes, para Pascal es dependiente del objeto y relativo a sus condiciones enunciativas. Suena, incluso a Foucault, de tan actual que es.

Descartes quiso deducir la física de los principios de la metafísica; Pascal no trata de hacer eso, sino, al revés, procedió inductivamente, 
a partir del problema que se proponía resolver. Si Descartes buscó lo apodíctico, Pascal prefirió lo verosímil.

Por este motivo, Pascal supuso una de las alternativas más fuertes al cartesianismo. Distinguió la pluralidad de planos, perspectivas y métodos, y se esforzó por pensar las distintas racionalidades que en cada caso resultan de aplicación. Los desafíos que plantea el mundo contemporáneo quizá aconsejan esta misma actitud (Villar, 2010, p. 267).

Pascal escribió una suerte de "discurso" del método en su opúsculo "Del espíritu geométrico y del arte de persuadir" (Pascal, 1987, pp. 9 y ss.). El método geométrico procede como la axiomática euclidiana, por definiciones, principios y demostraciones. Pero reconoce que es imposible definir y demostrar todo. Los primeros términos y enunciados tendrían que definirse y demostrarse, lo cual iría al infinito. Hay que parar en un punto, en ellos, y allí no interviene la demostración, sino la intuición (Kolakowski, 1996, pp. 179 y ss.).

Ese ideal solo se cumple en la geometría, y así lo que sobrepasa la geometría sobrepasa al hombre. De hecho, va más allá que Descartes, pues, dice que la geometría misma topa con ciertos conceptos, por ejemplo el de infinito, que no puede comprender, y que deja a la metafísica. A diferencia de Descartes, no es la metafísica la que lleva a la ciencia, sino la ciencia la que abre a la metafísica.

Las mismas nociones primeras y primeros principios solo se comprenden y se aceptan por intuición, por el corazón y no por la razón. Por otra parte, el arte de persuadir, la retórica, depende del espíritu de fineza, del corazón. Por eso, a diferencia de Descartes, no saca su teoría del conocimiento de la certeza geométrica, sino que parte de la probabilidad, y se acerca más a la retórica. Llega a decir que la mejor retórica sería la axiomática, como la de la geometría de 
Euclides, porque el único que conoce el corazón humano es Dios, que lo ha hecho (Pascal, 1987, p. 15). Anticipándose a Vico, dice que conocemos lo que hacemos, y el hombre ha hecho la geometría, mientras que Dios ha hecho al hombre, y es el único que puede comprender su corazón. Por eso, en Pascal, a pesar de tener un consumado espíritu geométrico, predominó el espíritu de la fineza, las razones del corazón, la retórica. También en eso se anticipó a Vico, que opuso la retórica o tópica a la crítica cartesiana.

Tanto Descartes como Pascal establecen la intuición y el raciocinio como los dos procesos del conocimiento. Pero mientras que para descartes los dos procesos son del intelecto, para Pascal la intuición es del corazón, y es el que asienta los principios.

El corazón capta de un modo inmediato los fundamentos de las verdades matemáticas. Sus conocimientos son más firmes que los que nos proporcionan nuestros razonamientos, que tienen que apoyarse en ellos. La razón deduce y demuestra. Es la facultad de las reglas; el corazón, de los principios. Sus funciones son complementarias. La razón conduce a definiciones precisas y comunicables. El corazón pertenece a lo individual y es difícil explicar a otro lo que uno siente (Villar, 2010, p. 268).

El corazón da los conocimientos iniciales de las ciencias, pero también las decisiones morales y trata los problemas existenciales. Hace las valoraciones y ordena la vida de acuerdo con ellas. Da la fundamentación del saber y el estímulo o motivo de la acción. Es la base del conocimiento y de la voluntad, así como la sede del afecto. Nos conduce a lo infinito y eterno. Por eso, Pascal se opone a los que exageran los alcances de la razón y de la ciencia. Acepta la contingencia, el azar y la oscuridad de la existencia humana. Por eso, no asigna tanto valor a la razón como Descartes. Y es lo que le da una gran actualidad. 
En su antropología, el hombre tiene razón y corazón, y en su epistemología el corazón viene a ser más importante que la razón misma. Su antropología está centrada en el corazón, es un ordo amoris, como el de san Agustín. En lugar de una egología en Pascal, se puede hablar de una agapología en él (Carraud, 1992, p. 323). Mientras que Descartes propone ese sujeto fuerte y prepotente, Pascal reconoce un sujeto descentrado y frágil. Insuficiente en muchas cosas, sobre todo, en el amor. Por eso, admite la necesidad de la gracia para tener caridad. El ser humano es una paradoja, como lo será para Kierkegaard. Da la impresión de que Pascal se asoma a los dos infinitos, el de lo enorme y el de lo minúsculo, y siente su pequeñez en medio de los dos. Se da cuenta de los desórdenes del hombre. No piensa en el estoicismo de Descartes, en su Tratado de las pasiones, sino que acepta la debilidad del hombre frente a la pasión. Por eso, se centra en lo que el ser humano hace para no pensar en ello: la diversión, la idolatría, etcétera.

El sujeto humano, el yo, es odioso, siempre se antepone. Quiere ser el centro de todo, de ahí su descentramiento. Comete injusticia, quisiera ser el amo de todos los demás. Y es un déspota con todos, disfrazado de cortesía. Es presa de su narcisismo. El yo de Descartes cree conocerse y dominarse; el de Pascal, ni se conoce ni domina sus inclinaciones, necesita de la gracia. Está más hundido en la inconsciencia y falla mucho en la moral. Solo un Dios puede salvarlo.

En suma, Pascal describe en sus Pensamientos a un hombre escindido, lábil y fragmentado. Es un monstruo incomprensible. Su grandeza, el pensamiento, no es sino conciencia de fragilidad y desdicha. La lucidez, por su parte, la experiencia del dolor propio asumido, se convierte en factor de dignificación personal (Villar, 2010, p. 271).

Tal parece que los intereses de Pascal eran opuestos a los de Descartes, y presenta un sujeto descentrado, inconsciente, inasible, lábil. Eso hace que no pueda colocárselo en el racionalismo sin más, 
sino en medio de este y de las otras opciones. Pascal es la paradoja viviente, como lo será más tarde Kierkegaard, conscientes de la fragilidad del hombre, como una caña, pero con una inmensa grandeza, pues, es una caña que piensa. Este equilibrio es el que le falta a muchos pensadores posmodernos, de la crisis del sujeto, y en esto reside la actualidad de Pascal.

Y es que Pascal atendió a la individualidad, como los existencialistas; pero también, y por lo mismo, a la alteridad, como los posmodernos. Sin embargo, no cometió la exageración de unos y otros, sino que se mantuvo en el medio, insistiendo en lo irrepetible que es cada uno, pero también en el hecho de que vivimos en comunidad, para lo cual se requiere un amor heroico, que es el de la caridad. Por eso, podemos decir que Pascal buscó, dentro de la desproporción que tanto captó, la proporción, difícil y exigua, pero suficiente para vivir y llegar a la Trascendencia. Es más, consigue la proporción a partir de la desproporción (Descotes, 1993, pp. 223 y ss.). Dios es desproporcionado para el hombre, pero puede proporcionarse a él. De ahí que podamos decir que tuvo mucho sentido de la proporción en medio de lo desproporcionado, lo cual es lo que, precisamente, hace la analogía. Fue, pues, un espíritu analógico, lo cual será considerado a continuación.

\section{PASCAL Y LA ANALOGÍA}

$\mathrm{Y}$ es que Pascal es eminentemente analógico, muy analogista. Lo es ya por el mismo colocarse en el entrecruce de las corrientes de su tiempo. Le tocó estar en las filas del racionalismo, por su conocimiento de Descartes, pero no es un racionalista típico, disiente mucho del iniciador de esta corriente en la modernidad. Critica a 
Descartes, pero no es irracionalista ni empirista; critica a los escolásticos, pero no es escéptico ni panteísta ni epicúreo ${ }^{1}$.

Otra cosa en la que se ve su espíritu de proporción o de analogía es frente a la ciencia, la joya de su tiempo. Se coloca en el intermedio del cientificismo y el fideísmo, pues, no es lo uno ni lo otro. Ama la ciencia, pero critica los excesos de confianza en la razón que cometen los científicos de su momento. Ama la fe, pero no la desconecta totalmente de la razón. Por eso, en lugar de adoptar la prueba anselmiana, como hizo Descartes, propone esa prueba tan atípica (más pragmática) que fue la de la apuesta.

Es analógico, sobre todo, en su distinción entre el espíritu geométrico y el espíritu de fineza. El primero atiende a las razones de la razón, y el segundo a las del corazón. Por ello, el primero tiende a ser unívoco y el segundo equívoco. Pero Pascal los quiere equilibrar, proporcionalmente, en el individuo. De ahí que tenga como ideal del sabio alguien que conjunte y balancee los dos espíritus, aunque acepta que es algo muy difícil de lograr.

Así, aunque aprecia mucho la razón, da cabida a la intuición, al corazón. En su idea de combinar el espíritu de geometría y el espíritu de fineza está una pauta analógica. También lo es la idea de testimonio. En su misma epistemología se ve esto, ya que adopta el punto de vista fijo, que es analógico, un perspectivismo analógico, que abarque lo más que se pueda los demás enfoques, sin encerrarse en ninguna perspectiva opuesta, sino buscando una más amplia.

Lo es, incluso, en ese balancear el peso que tiene la razón geométrica y el que tiene el corazón y su fineza. Este último es el dueño de

"Todos los principios son verdaderos: los de los pirronianos, los de los estoicos, los de los ateos, etc. Pero sus conclusiones son falsas, porque los principios opuestos son verdaderos también" (Pascal, 1984 , n. 389). 
la intuición, mientras que aquella lo es del raciocinio, del discurso. Pero los principios no se aceptan por razonamiento o argumentación, sino por intuición, por la aceptación que les da el sentimiento, el corazón. Ya desde el origen del racionalismo y el cientificismo, Pascal se esforzó por encontrar el lugar que ocupa el sentimiento en el conocimiento, anticipándose a lo que ahora hacen muchos epistemólogos que estudian la injerencia de los sentimientos en el conocimiento científico.

Se asemeja a otro pensador posterior, muy analógico también, que fue Vico. Al igual que él, cuestionó la crítica, que era la esencia del cartesianismo, y defendió la retórica o tópica. Era su gran sensibilidad hacia lo contingente, particular y verosímil, enfrentado a lo necesario, universal y apodíctico. No negó ni prohibió la crítica, pero la compensó con la tópica, al modo como pidió equilibrar el espíritu geométrico con el espíritu de fineza, que es el que guía el arte de persuadir, propio, evidentemente, de la retórica. Por ello, llegó a decir que la verdadera retórica se mofa de la retórica.

Asimismo, se encuentra un profundo analogismo en la antropología filosófica de Pascal. En efecto, critica el yo o sujeto cartesiano, autoposeído y translúcido, pero no cae en el yo o sujeto completamente abatido y debilitado de muchos posmodernos. Su postura es equilibrada y proporcional, descentrando al sujeto, es decir, quitándolo del centro del universo, por el vértigo que le produjeron los dos infinitos, el de lo grande y el de lo pequeño, y quitándolo de la ventana en la que lo veía Descartes. Mostró su insuficiencia cognoscitiva y su mezquindad volitiva, así como su incapacidad moral, pero no lo condenó al fracaso, es decir, no adoptó una postura equívoca respecto de él, sino una postura analógica. La del claroscuro, la ambigüedad que tiene cierta claridad, o que puede alcanzarla. 
Sortea el racionalismo apologético de Descartes y el fideísmo pirrónico de Montaigne. Le adjudica valor y fuerza a la razón, pero también límites muy precisos. Y asigna una gran necesidad a la fe, porque ni siquiera en las cosas naturales alcanzamos plena certeza, y requerimos ser ayudados por ella. Tal es su analogía de la razón y la fe, ni pura analogia entis ni pura analogia fidei. También habría que decir que es una analogia libertatis, pues, tampoco la libertad es omnímoda, por las limitaciones de la voluntad para dirigir al hombre en medio de las pasiones. A diferencia del estoicismo de Descartes en su Tratado de las pasiones, Pascal se queda en una especie de epicureísmo cristiano, como el de Quevedo, que consiste en buscar la dominación de la pasión mediante el placer que da lo intelectual y la amistad.

Más bien lo analógico aquí, en su antropología, es el lugar que da al amor. El amor conecta la razón y el corazón; necesita de los dos. Por supuesto que no es pura razón, la cual puede ser solo calculadora, y en ese sentido o medida excluir el amor. Pero tampoco es mera visceralidad, corazón abierto, sino un amor conforme con la prudencia, en la línea agustiniana, y con un gran sentido analógico. Es el amor verdadero.

En esa misma antropología filosófica, en lugar de quedarse en la caída del sujeto, se le ve más bien en la línea del último Foucault, de los procesos de la formación de la subjetividad, pues, se interesa en el modo como el hombre puede salir de su egoísmo, de su vanidad, de sus diversiones e ir más allá de la moral del gentilhombre, y, por supuesto, más allá de la de los libertinos. Es una verdadera epimeleia, un cuidado de sí, que se logra con los ejercicios espirituales y la dirección de la conciencia, como la que hacían con mucha profundidad y dedicación los de Port-Royal. 
Esa idea de poner al yo o al sujeto en su sitio, de buscar su lugar en el cosmos, es, sobre todo, deseo de dominar el egoísmo o narcisismo, de mitigar la injusticia que el yo cartesiano hace al ponerse a sí mismo en el centro de la atención del universo, es una consecuencia de su postura analógica. El hombre es el centro, pero no como centro de atención, sino para servir de conciencia y de amor a todas las cosas, como reflejo de todo, como espejo en el que los demás seres se miran, se encuentran. No es, pues, el centro de atención, sino de recuperación. Fue descentrado para ocupar de verdad su sitio en el centro. Es decir, después de su saludable deconstrucción, viene su apropiada reconstrucción.

Donde se ve el analogismo de Pascal muy a las claras es en un fragmento de su antropología filosófica, que se titula precisamente "La grandeza de la humanidad está en el medio". Lo considera pirronismo, y dice:

El espíritu extremo es acusado de locura, como el extremo defecto. No más que la mediocridad es buena. Es la multitud la que ha establecido esto, y la que zahiere a quien escapa por cualquier extremo. Yo no me obstinaré, yo consiento que se me ponga allí, y rehúso estar en el extremo inferior, no porque es inferior, sino porque es extremo; porque yo rehusaría lo mismo que se me pusiese en lo alto. Es salir de la humanidad, salir del medio. La grandeza del alma humana consiste en saber estar allí; tan necesario es que la grandeza esté en salir de allí, como ella lo es en no salir (Pascal, 1984, n. 327).

Ni ensalzar al hombre ni vilipendiarlo, es el término medio: no en cuanto centro del universo, porque este es infinito, hacia arriba y hacia abajo, sino como el que está entre los ángeles y las bestias; y si quiere ser ángel, acabará viviendo como bestia. Ni ángel ni bestia, por eso, llama al hombre "monstruo incomprensible" (Pascal, 1984, n. 330). 
Hay que decir, además, que, en Pascal, la analogía es "antropoteológica” (Secretan, 1998, pp. 27 y ss.). Junta al hombre y a Dios, tiene a Dios como centro, más que al hombre. Es la confluencia del lenguaje humano y del divino, de la naturaleza y la gracia. En moral, pide un equilibrio proporcional en las virtudes, un término medio en todo, que es el de la prudencia. Pero da un lugar muy grande a la acción de la gracia divina, experimentado y consciente de la insuficiencia del ser humano. El hombre no alcanza por sí mismo el bien, sin la ayuda del que es el Bien por excelencia.

Es analogista en su teoría del lenguaje, de la interpretación y de la retórica. En su carta 4 a mademoiselle de Roannez, dice que hay dos sentidos perfectos en la Escritura: el literal y el místico ${ }^{2}$. Y el místico es literalmente místico, al igual que el literal es místicamente literal. Así como allí habla de un Dios escondido, se puede hablar de una doctrina del sentido escondido del lenguaje. El lenguaje humano solo cobra sentido por su integración a la Palabra de Dios.

Según Philibert Secretan, en Pascal hay una analogía entre los tres órdenes del ser: los cuerpos, los espíritus y Dios. Entre los cuerpos y los espíritus hay una distancia infinita, y entre el hombre y Dios hay una distancia infinitamente infinita. Por eso, es una analogia figurationis per modum disproportionalitatis (se tocan el infinito y la figura). Pascal tenía una aguda conciencia de la desproporción entre lo creado y el Creador. Hay una cercanía a la inconmensurabilidad entre uno y otro, y casi una teología negativa. En todo caso, un gran respeto. $\mathrm{Y}$ es analogía de figuración porque un orden es figura del otro, es un ícono suyo (por ejemplo el del hombre y el de Dios) (Secretan, 1998, pp. 27 y ss.).

2 "Podemos añadir a esas consideraciones el Espíritu de Dios oculto en las Escrituras. Pues tiene dos sentidos perfectos, el literal y el místico" (Pascal, 1996, p. 100). 
Todos los cuerpos no valen lo que el menor de los espíritus, y todos los cuerpos y los espíritus no valen lo que el menor impulso de la caridad. Pero entre unos y otros hay analogía, iconicidad; en el sentido de que la caridad se vale del espíritu, y este del mundo material, para poder actuar. El hombre es capaz de conocer la verdad y de hacer el bien, pero tiene que comprender que no los tiene por sí mismo, sino en el mundo y por la gracia. Como vimos, el hombre se mueve entre esos dos extremos, de la razón y la pasión, la virtud y el vicio, a lo cual Pascal dice: "Sea; pero, al menos, esto denota la agilidad del alma, si ello no denota la extensión” (Pascal, 1984, n. 323). Y así se rompe esa dicotomía entre la cosa pensante y la cosa extensa; el alma es pensante pero también tiene extensión, la amplitud que le confiere su agilidad. Allí se rebasa la distensión que ponía Descartes entre pensamiento y extensión.

\section{REFLEXIONES DESDE LA HERMENÉUTICA ANALÓGICA}

La actitud analogista de Pascal, su anhelo de proporción en medio de la desproporción, nos enseña que una hermenéutica analógica tiene que mediar entre el sentido literal y el sentido místico o espiritual (de hecho, es el sentido no literal, el alegórico en general). Esto equivale a mediar entre la razón y el corazón, entre el intelecto y el afecto. Pero da preeminencia al corazón, es decir, al amor. Al cabo, la crítica de la razón ejercerá el equilibrio que se necesita, por tensión en contra del corazón. Es el equilibrio proporcional entre el espíritu geométrico y el espíritu de fineza, lo cual conduce al verdadero arte de persuadir. Este se basa en la razón, pero también en el corazón, en el movimiento de las pasiones, como ya decía Aristóteles. 
De Pascal también se aprende una hermenéutica analógica, el valor de lo contingente, individual y verosímil frente a lo necesario, universal y apodíctico. Las más cosas del mundo de la vida son particulares y movedizas, por eso, están supeditadas a la prudencia, que es la virtud de la analogía por excelencia. Y también son objeto de la retórica, la cual versa, eminentemente, sobre lo cotidiano, y usa argumentos muy en la línea de lo analógico.

Supone un yo o sujeto lábil, fragmentado y descentrado, pero lo suficientemente resistente como para el mundo de la vida. Es el yo de la hermenéutica y de la retórica, el sujeto narrativo y moral que está detrás de esa postura filosófica analógica. No es un sujeto unívoco, como el cartesiano, ni tampoco un sujeto equívoco, como el pirrónico, sino un sujeto analógico, como el que nos puede servir hoy en día, después de las críticas de Foucault.

Tiene un concepto de ser humano pasado por la deconstrucción y luego por la reconstrucción. En eso consiste la analogía: en que el sujeto unívoco fue sometido a la deconstrucción de la equivocidad, pero es recuperado en la reconstrucción de la analogía.

Además, encuentro en Pascal una analogia amoris, una analogía del amor. En efecto, hay distintos amores: unos son de la verdadera libertad y otros del libertinaje. Por eso, hay que encontrar esas diferencias. Él lo sitúa en el medio, en esa confluencia del amor interesado (que nos toca como seres humanos, ya que solo Dios podría ser desinteresado), y es lo que avala el argumento de la apuesta. Parte de pragmatismo y parte de desinterés. Es el ordo amoris, de san Agustín; y al ser un orden, es analogía, ya que el orden es analogía aplicada, proporción puesta en las cosas. Y, por lo tanto, el amor tiene su orden, su debida proporción, su analogía (así no se confunde ni se entiende equívocamente el “Ama y haz lo que quieras", de Agustín). De esta manera, encontramos un sujeto carente y descentrado, pero, a pesar 
de sus deficiencias, sobre todo, de su insuficiencia en el amor, alcanza a hacer el bien, tiene la capacidad o posibilidad del bien.

\section{CONCLUSIÓN}

Estamos aquí, donde nos ha depositado Pascal. Este genio de la ciencia fue también connotado en el corazón, en los sentimientos, en el afecto, y ese equilibrio proporcional es el que le gana el apelativo de analógico. Él nos da muchas enseñanzas en el camino de la analogía, para lograrla adecuadamente.

Por eso, también nos ha sido útil para una hermenéutica analógica, con varias lecciones inapreciables. Nos enseña, sobre todo, a apostar a una hermenéutica así, cuyos resultados estaremos viendo hasta el final, hasta lo último recogeremos sus frutos. 